\title{
Wideband Rectangular Foldable and Non-foldable Antenna for Internet of Things Applications
}

\author{
Steve W. Y. Mung $\mathbb{D}^{1,2}$ Cheuk Yin Cheung, ${ }^{3}$ Ka Ming Wu, ${ }^{1}$ and Joseph S. M. Yuen ${ }^{1}$ \\ ${ }^{1}$ Innovation Technology Co. Ltd., Hong Kong \\ ${ }^{2}$ Department of Electronic and Information Engineering, The Hong Kong Polytechnic University, Hong Kong \\ ${ }^{3}$ Independent Researcher, Hong Kong
}

Correspondence should be addressed to Steve W. Y. Mung; mungwaiyin@hotmail.com

Received 13 November 2018; Revised 19 February 2019; Accepted 25 February 2019; Published 2 May 2019

Guest Editor: Thamer Almoneef

Copyright (c) 2019 Steve W. Y. Mung et al. This is an open access article distributed under the Creative Commons Attribution License, which permits unrestricted use, distribution, and reproduction in any medium, provided the original work is properly cited.

\begin{abstract}
This article presents a simple wideband rectangular antenna in foldable and non-foldable (printed circuit board (PCB)) structures for Internet of Things (IoT) applications. Both are simple structures with two similar rectangular metal planes which cover multiple frequency bands such as GPS, WCDMA/LTE, and $2.4 \mathrm{GHz}$ industrial, scientific, and medical (ISM) bands. This wideband antenna is suitable to integrate into the short- and long-range wireless applications such as the short-range $2.4 \mathrm{GHz}$ ISM band and standard cellular bands. This lowers the overall size of the product as well as the cost in the applications. In this article, the configuration and operation principle are presented as well as its trade-offs on the design parameters. Simulated and experimental results of foldable and non-foldable (PCB) structures show that the antenna is suited for IoT applications.
\end{abstract}

\section{Introduction}

The Internet of Things (IoT) involves data interconnection and exchange between devices and/or sensors $[1,2]$. At present, with the explosive development of IoT techniques, increasing applications are found in various fields, including security, tracking, agriculture, smart metering, smart city, and smart home. IoT applications have specific requirements, such as low data rate, low energy consumption, and cost efficiency. Known short-range radio techniques (such as ZigBee and Bluetooth under $2.4 \mathrm{GHz}$ industrial, scientific, and medical (ISM) bands) are not suitable for scenarios of long-distance transmission but with low power consumption [3]. The technical solution based on cellular communications (such as 2G, 3G, and 4G cellular standards) provides larger coverage [4], but it consumes too much power.

There are many size-reduced individual antenna solutions for the 2.4 GHz ISM band [5-7] or cellular standards [8,9]. Different structures of antenna were proposed to combine these two applications into one broadband antenna $[10,11]$ which reduces the overall area compared to two individual antennas used. This article proposes a broadband antenna for the short-range $2.4 \mathrm{GHz}$ ISM band and cellular standards to have simultaneous emission and reception. This proposed structure has the simple foldable advantage compared to other broadband antennas $[10,11]$. In this article, the foldable and nonfoldable antenna design and experimental result are individually presented for different uses in IoT applications. Each individual section shows its design structure and its parameters as well as the simulation of these parameters. Foldable and non-foldable designs were fabricated with experimental results in each section. The bandwidth of both designs is more than $65 \%$, and the operating frequency covers the applications in the global positioning system (GPS), the $2.4 \mathrm{GHz}$ ISM band, and the common 3GPP WCDMA bands as well as the LTE bands. The radiation performance of the non-foldable PCB design is also presented, which shows that this proposed configuration is suitable for simultaneous short-range and long-distance techniques in IoT applications.

\section{Antenna Configuration and Operation}

A dipole antenna [12] is one of the simple antennas in wireless application, which consists of two identical conductive 


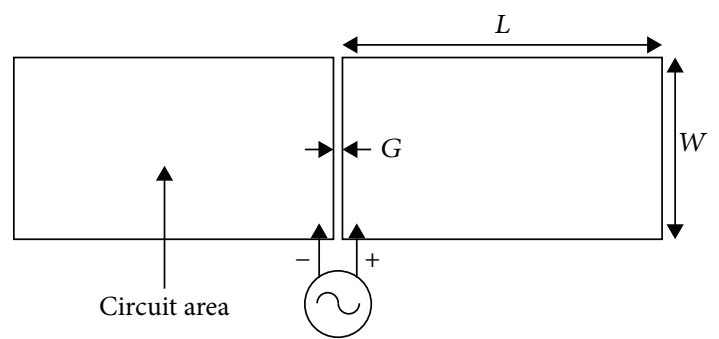

Figure 1: Proposed antenna.

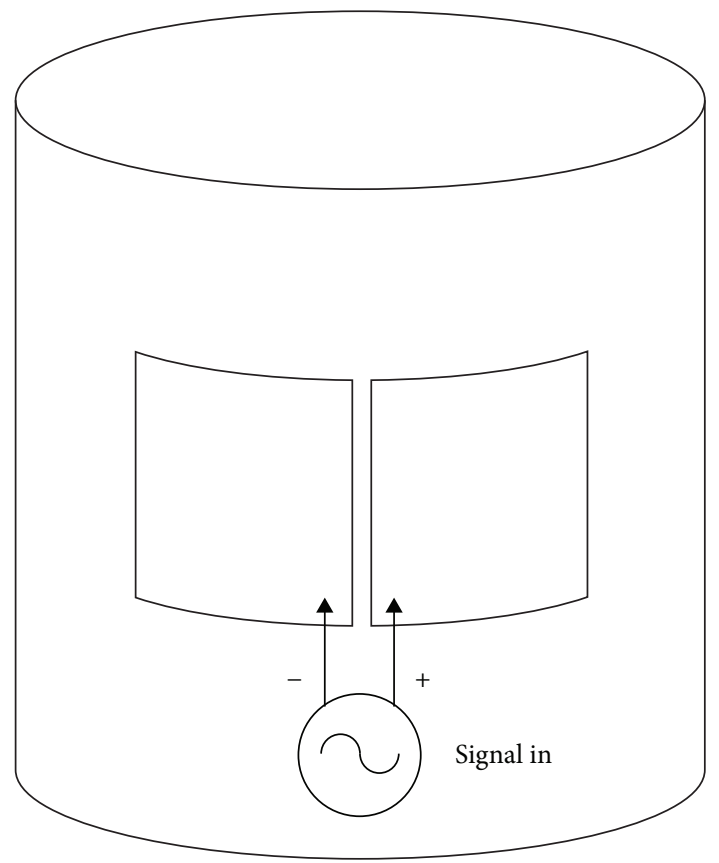

Figure 2: Foldable characteristic in operation.

elements. Theoretically, its length is required to be a half wavelength (0.5 $\lambda)$ for maximum response [12], and a thicker dipole provides wider bandwidth [13]. The geometry of the proposed planar antenna is shown in Figure 1, which is similar to the dipole antenna. This antenna has a simple structure with two similar rectangular metal planes $(L \times W)$ with a gap $(G)$ between the two metal planes for wideband operation. The design parameters are the width $(W)$, length $(L)$, and gap $(G)$ as well as the substrate's height $(h)$ and dielectric constant $\left(\varepsilon_{r}\right)[13]$. The circuit can be placed in the negative metal planes (the left side of the metal plane in Figure 1) which is normally the circuit's ground area. This proposed antenna can be backed by a ground plate for the circuit [13] as well as allow for its foldable characteristic as seen in Figure 2.

\section{Foldable Antenna Design and Experimental Result}

Figure 3 shows the fabricated foldable antenna which contains two similar rectangular metal sheets $(L \times W)$, and the gap $(G)$ between the two metal planes is $1 \mathrm{~mm}$. Figure 4

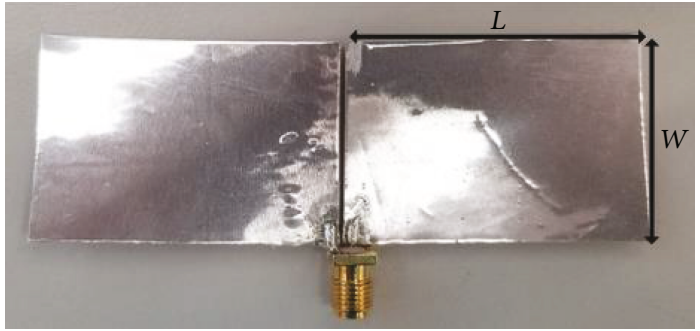

FIgURE 3: Foldable antenna.

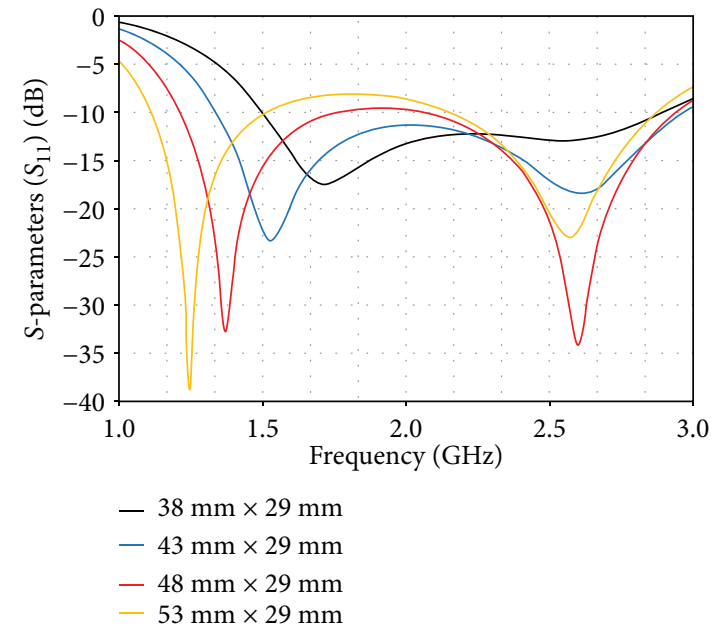

FIgURE 4: Simulated $S$-parameters: $S_{11}$ of foldable antenna with different lengths.

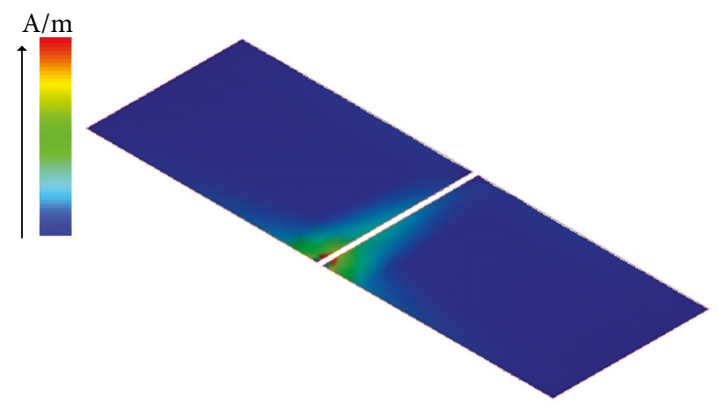

Figure 5: Simulated current distribution (frequency $=1.5 \mathrm{GHz}$, with $L=43 \mathrm{~mm}$ and $W=29 \mathrm{~mm}$ ).

shows the return losses of this foldable antenna with different lengths of sheets $(L)$ and fixed width $(W=29 \mathrm{~mm})$. The results show that this foldable structure has wideband operation and the frequency range is shifted to the lower side with a longer length $(L)$ because the length $(L)$ is closer to the quarter-wavelength of a lower frequency.

Figure 5 shows the simulated current distribution under $1.5 \mathrm{GHz}$ with $L=43 \mathrm{~mm}$ and $W=29 \mathrm{~mm}$, and Figure 6 shows the simulated and measured results of this fabricated foldable antenna in Figure 5. It shows that the simulated and measured results are close to each other with the bandwidth 


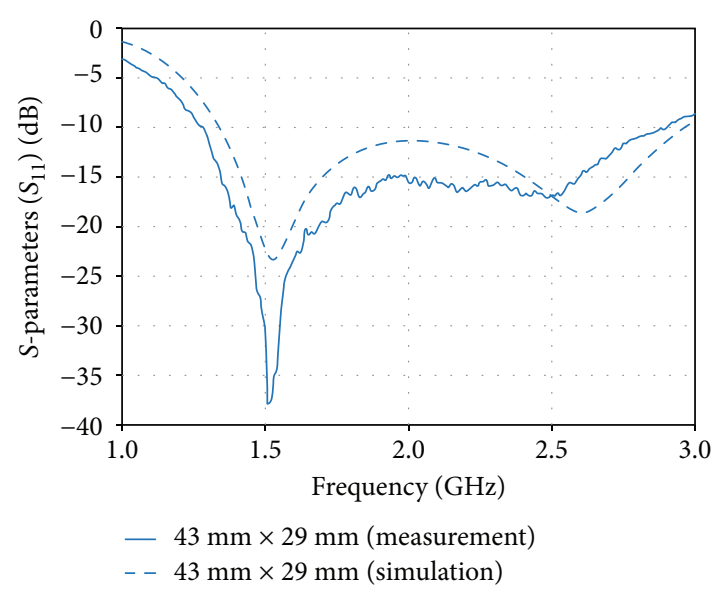

FIGURE 6: Simulated and measured $S$-parameters: $S_{11}$ of foldable antenna.

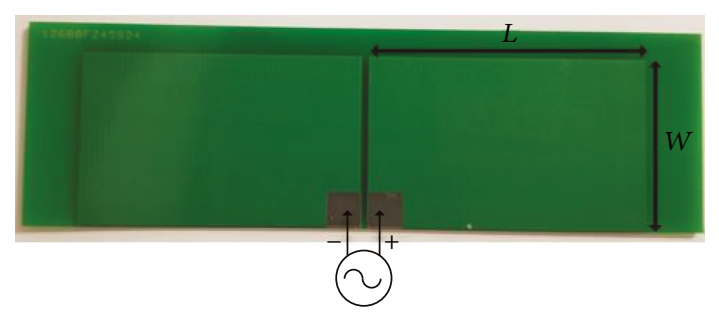

Figure 7: Non-foldable PCB antenna.

of $76 \%$ from $1.3 \mathrm{GHz}$ to $2.9 \mathrm{GHz}$. This range covers the applications in GPS, the $2.4 \mathrm{GHz}$ ISM band, and the common 3GPP WCDMA bands and LTE bands.

\section{Non-foldable Antenna Design and Experimental Result}

In another prototype, a non-foldable antenna was designed and fabricated on an FR4 printed circuit board (PCB) with a dielectric constant of 4.6 and thickness of $0.8 \mathrm{~mm}$, and the gap $(G)$ between two metal planes is $1 \mathrm{~mm}$. This nonfoldable antenna contains two similar rectangular copper planes $(L \times W)$ on the FR4 substrate (PCB) shown in Figure 7. The simulated results with different lengths of $L$ and fixed width $(W=25 \mathrm{~mm})$ are shown in Figure 8 . This non-foldable design also shows that the frequency is shifted to the lower side if length $(L)$ is longer. Figure 9 shows the simulated and measured results with $L=36 \mathrm{~mm}$ and $41 \mathrm{~mm}$ (same width of $W=29 \mathrm{~mm}$ ). The current distribution of this design is similar to those in Figure 5. Simulated and measured results show that they are close to each other with the bandwidth of $76 \%$ from $1.35 \mathrm{GHz}$ to $2.75 \mathrm{GHz}$, which is little worse than the foldable design in Figure 6. The radiation patterns are carried out by an antenna measurement system, and Figure 10 shows the measured radiation patterns of this non-foldable design at frequencies under $1.575 \mathrm{GHz}, \quad 1.75 \mathrm{GHz}, \quad 1.95 \mathrm{GHz}$, and $2.45 \mathrm{GHz}$ which are the frequency bands of GPS, WCDMA/LTE,

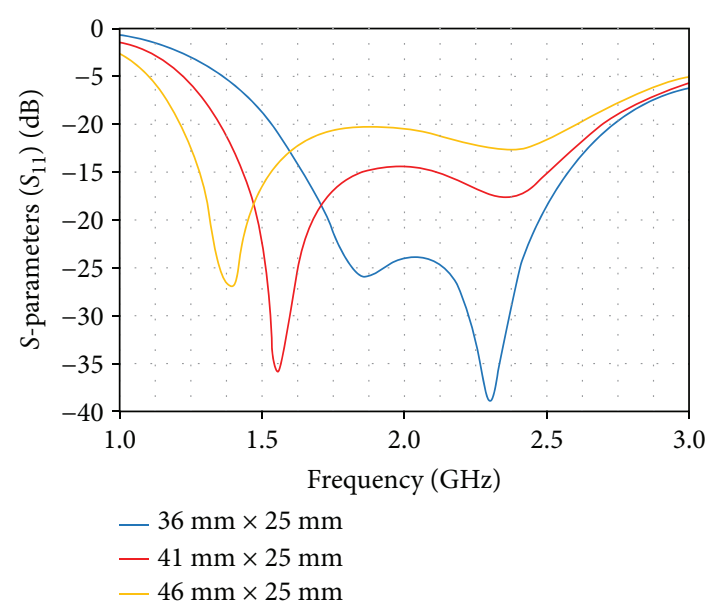

FIgURE 8: Simulated S-parameters: $S_{11}$ of non-foldable PCB antenna with different lengths.

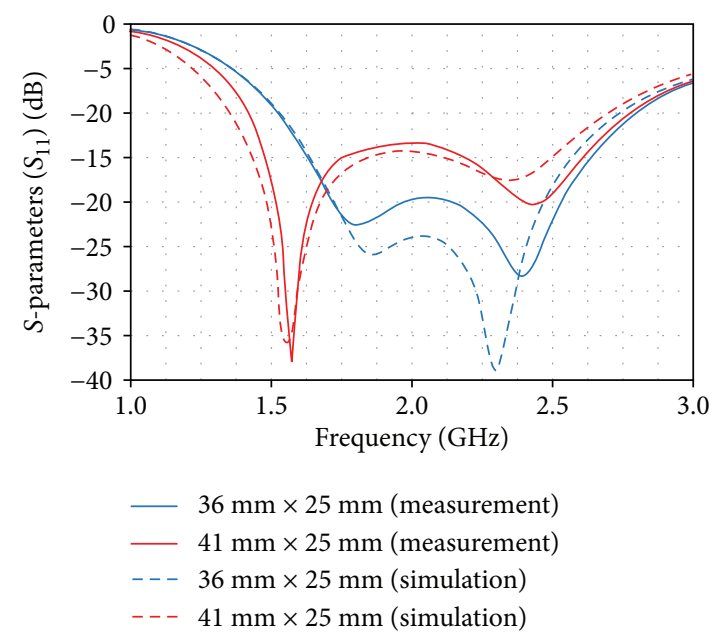

FIgURE 9: Simulated and measured $S$-parameters: $S_{11}$ of nonfoldable PCB antenna.

and the $2.4 \mathrm{GHz}$ ISM band, respectively, and the gain with different bands is also shown in Figure 11.

\section{Conclusions}

This paper proposes an antenna with simple foldable and non-foldable structures for IoT applications. To elaborate on the structures, both foldable and non-foldable structures were individually proposed and fabricated for their different uses in IoT applications. Both measurement results of two structures show more than $65 \%$ in bandwidth. Their operating frequency covers IoT applications in GPS, the $2.4 \mathrm{GHz}$ ISM band, and the common 3GPP WCDMA and LTE bands. In the non-foldable structure, the gain performances showed that it has good performances compared to the multiple antennas used in individual bands. This wideband, planar, and low-cost (PCB) antenna is one of the suitable and good choices in IoT applications, especially the foldable structure which can be used in wearable applications. 

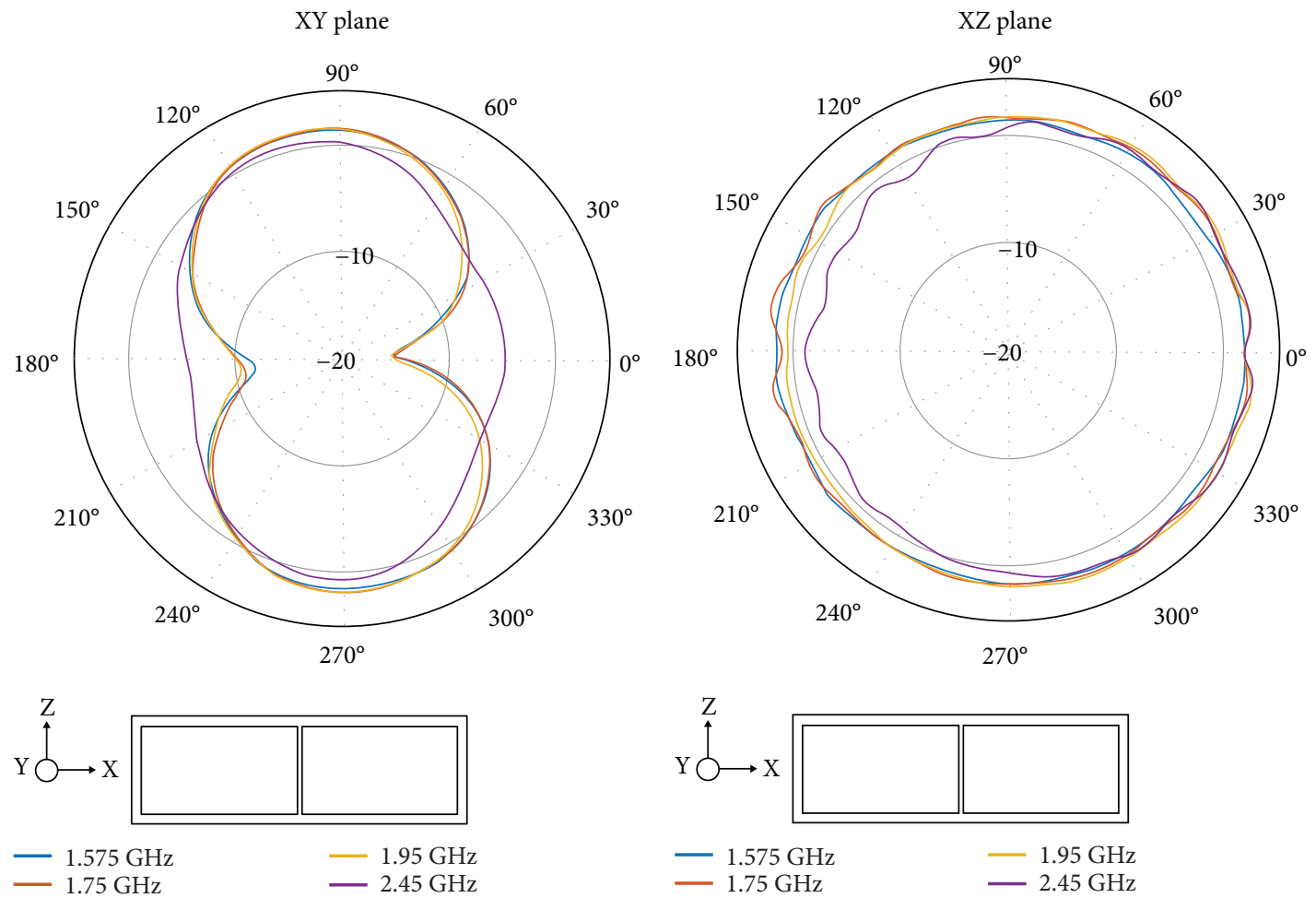

(a)

(b)
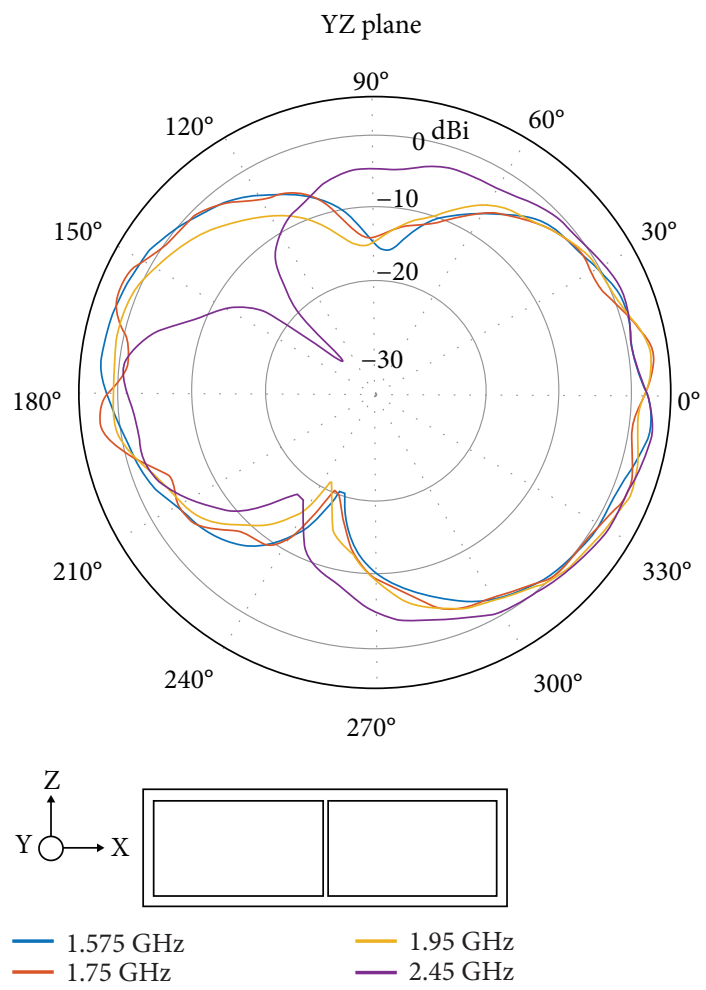

(c)

FIGURE 10: Measured radiation patterns in gains (dBi): (a) XY plane $\left(\theta=90^{\circ}\right)$, (b) XZ plane $\left(\varphi=90^{\circ}\right)$, and $(\mathrm{c}) \mathrm{YZ}$ plane $\left(\varphi=0^{\circ}\right)$. 


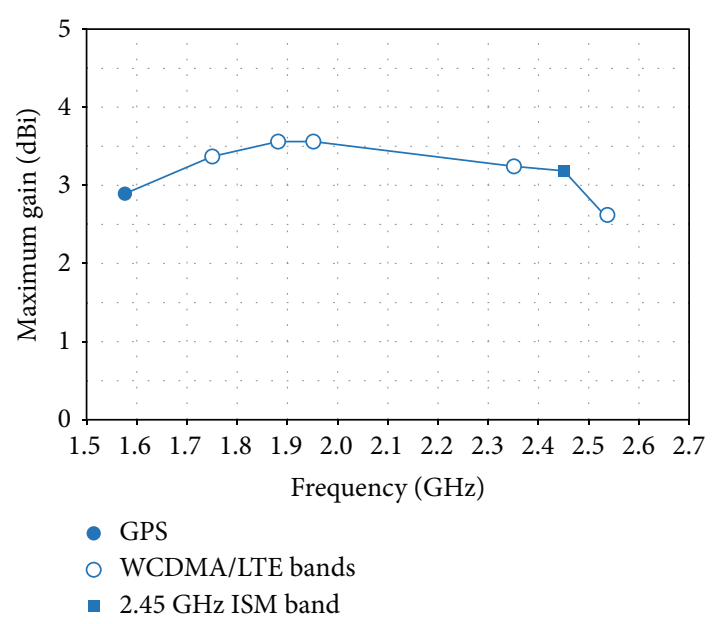

Figure 11: The maximum gain $(\mathrm{dBi})$ of the non-foldable PCB antenna.

\section{Data Availability}

The data used to support the findings of this study are available from the corresponding author upon request.

\section{Conflicts of Interest}

The authors declare that there is no conflict of interest regarding the publication of this paper.

\section{Acknowledgments}

This work was supported by the Innovation Technology Company Limited, Hong Kong.

\section{References}

[1] P. Suresh, J. Vijay Daniel, V. Parthasarathy, and R. H. Aswathy, "A state of the art review on the internet of things (IoT) history, technology and fields of deployment," in 2014 International Conference on Science Engineering and Management Research (ICSEMR), Chennai, India, November 2014.

[2] S. B. Baker, W. Xiang, and I. Atkinson, "Internet of things for smart healthcare: technologies, challenges, and opportunities," IEEE Access, vol. 5, pp. 26521-26544, 2017.

[3] https://www.bluetooth.com.

[4] http://www.3gpp.org.

[5] C. Y. Cheung, J. S. M. Yuen, and S. W. Y. MUNG, "Miniaturized printed inverted-F antenna for internet of things: a design on PCB with a meandering line and shorting strip," International Journal of Antennas and Propagation, vol. 2018, Article ID 5172960, 5 pages, 2018.

[6] D. Seo, S. Jeon, N. Kang, J. Ryu, and J.-H. Choi, "Design of a novel compact antenna for a Bluetooth LTCC module," Microwave and Optical Technology Letters, vol. 50, no. 1, pp. 180-183, 2008.

[7] L. K. Yeung, J. Wang, Y. Huang, S. C. Lee, and K. L. Wu, “A compact LTCC Bluetooth system module with an integrated antenna," International Journal of $R F$ and Microwave Computer-Aided Engineering, vol. 16, no. 3, pp. 238-244, 2006.
[8] K.-L. Wong, S.-W. Su, C.-L. Tang, and S.-H. Yeh, "Internal shorted patch antenna for a UMTS folder-type mobile phone," IEEE Transactions on Antennas and Propagation, vol. 53, no. 10, pp. 3391-3394, 2005.

[9] X. Xiao, W.-H. Zong, S.-D. Li, X.-Y. Wei, and X.-Y. Qu, "A wideband slot antenna for mobile phone applications," in 2016 IEEE 5th Asia-Pacific Conference on Antennas and Propagation (APCAP), Kaohsiung, Taiwan, July 2016.

[10] J.-H. Chen, C.-J. Ho, C.-H. Wu, S.-Y. Chen, and P. Hsu, "Dualband planar monopole antenna for multiband mobile systems," IEEE Antennas and Wireless Propagation Letters, vol. 7, pp. 769-772, 2008.

[11] R. L. Li, B. Pan, J. Laskar, and M. M. Tentzeris, "A compact broadband planar antenna for GPS, DCS-1800, IMT-2000, and WLAN applications," IEEE Antennas and Wireless Propagation Letters, vol. 6, pp. 25-27, 2007.

[12] J. D. Kraus and R. J. Marhefka, Antennas: For All Applications, McGraw-Hill, 2002.

[13] J. I. Kim, B. M. Lee, and Y. J. Yoon, "Wideband printed dipole antenna for multiple wireless services," in Proceedings RAWCON 2001. 2001 IEEE Radio and Wireless Conference (Cat.No.01EX514), pp. 153-156, Waltham, MA, USA, August 2001. 


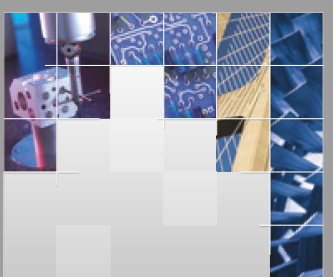

\section{Enfincering}
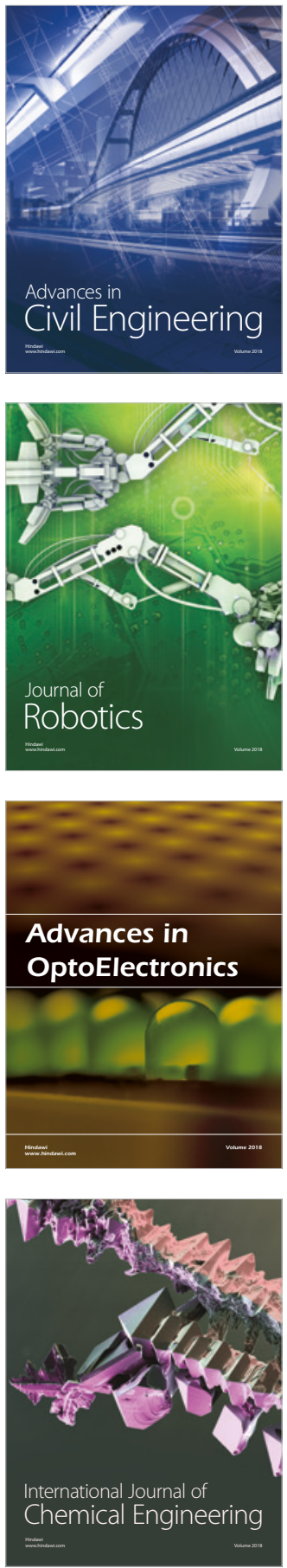

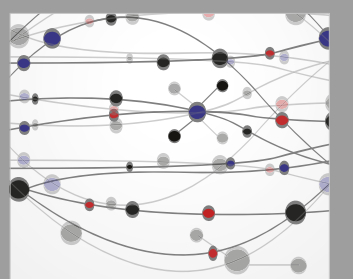

\section{Rotating \\ Machinery}

The Scientific World Journal

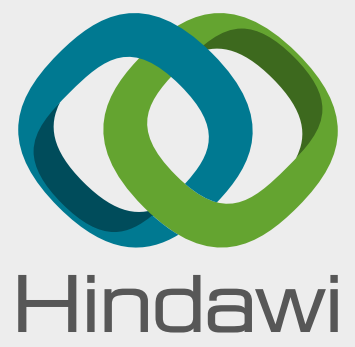

Submit your manuscripts at

www.hindawi.com
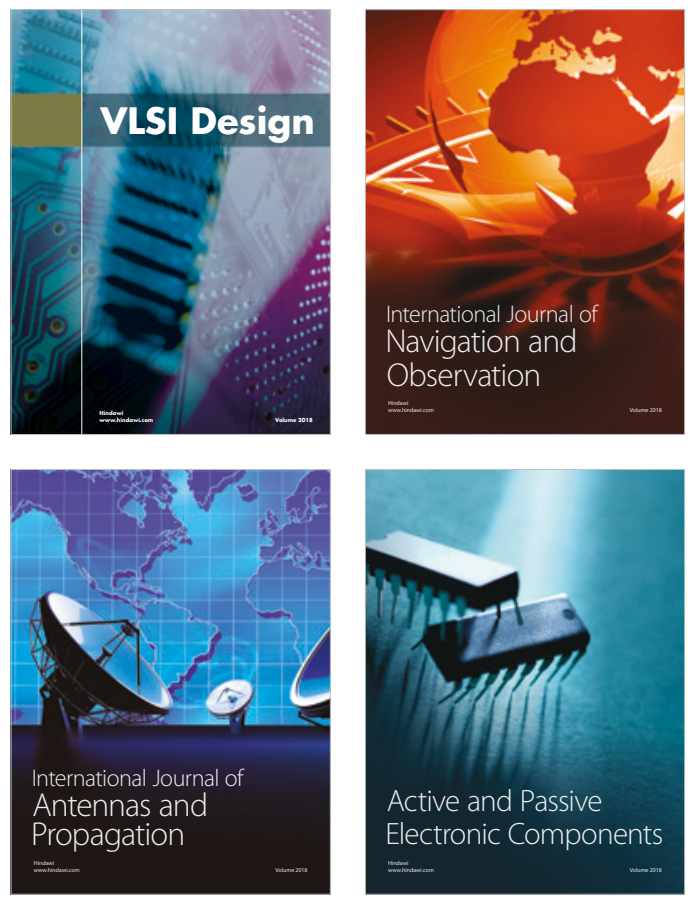
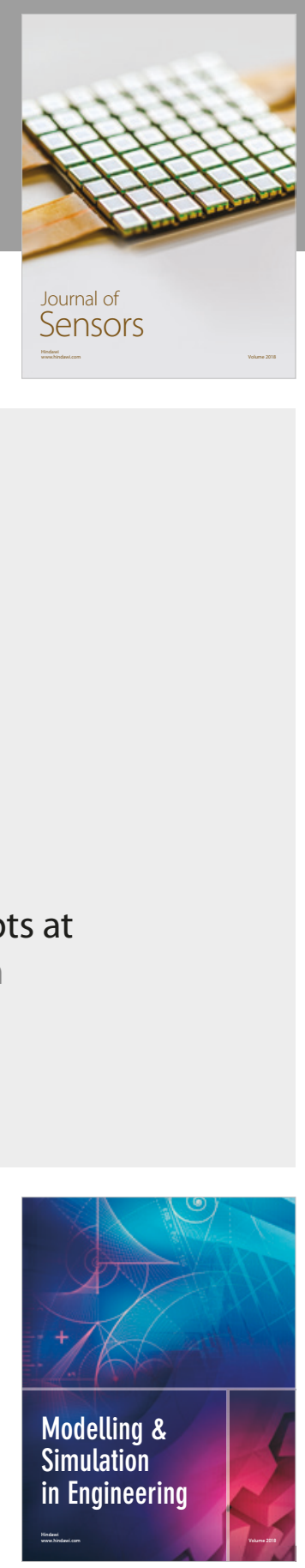

\section{Advances \\ Multimedia}
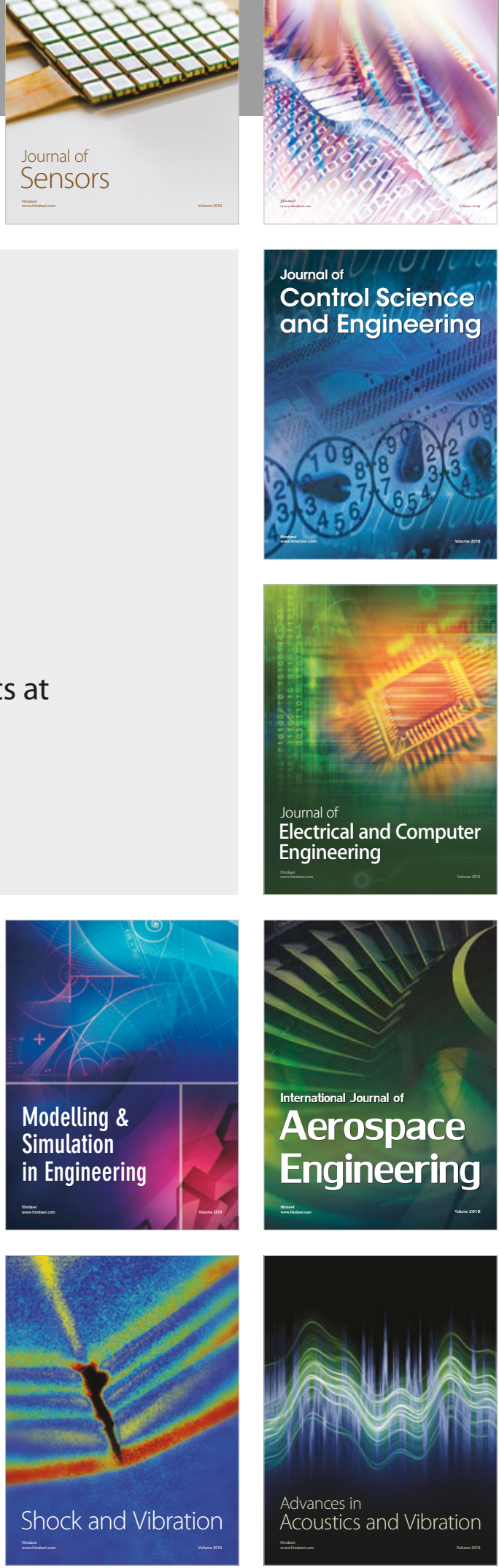